\title{
MỘT SỐ VẤN ĐỀ VỀ HợP ĐỒNG THỬ VIÊC TRONG BỘ LUẬT LAO ĐỘNG NĂM 2012
}

\author{
Nguyễn Văn Tố Hũ̃u ${ }^{a^{*}}$
}

${ }^{a}$ Khoa Chính trị - Luật, Truờng Đại học Kiên Giang, Kiên Giang, Việt Nam

"Tác giả liên hệ: Email: nvthuu@vnkgu.edu.vn

Lịch sử bài báo

Nhận ngày 13 tháng 05 năm 2018

Chỉnh sửa ngày 10 tháng 06 năm 2018 | Chấp nhận đăng ngày 28 tháng 06 năm 2018

\section{Tóm tắt}

Quy định chặt chẽ về hợp đồng thư việc (HĐTV) nhằm đảm bảo quyền, lợi ích hợp pháp của ngườ lao động (NLĐ) và người sủ dụng lao động (NSDLĐ) trong thời gian thư việc. Bộ luật Lao động (BLLĐ) năm 2012 và các văn bản hướng dẫn thi hành có nhiều quy định mới về HĐTV nhưng vẫn tồn tại nhũng hạn chế nhất định. Bài viết sẽ trình bày khái quát chung về HĐTV, sự phát triển quy định về HĐTV qua các giai đoạn cũng nhu phân tích, chỉ rõ nhũng bất cập trong quy định hiện hành về HĐTV.

Từ khóa: Hợp đồng thử việc; Lao động; Thử việc.

Mã số định danh bài báo: http://tckh.dlu.edu.vn/index.php/tckhdhdl/article/view/469

Loại bài báo: Bài báo nghiên cứu gốc có bình duyệt

Bản quyền @ 2018 (Các) Tác giả.

Cấp phép: Bài báo này được cấp phép theo CC BY-NC-ND 4.0 


\title{
SOME ISSUES RELATED TO PROBATION CONTRACT UNDER LABOR CODE 2012
}

\author{
Nguyen Van To Huu ${ }^{a^{*}}$ \\ ${ }^{a}$ The Faculty of Politics - Law, Kiengiang University, Kiengiang, Vietnam \\ *Corresponding author: Email: nvthuu@vnkgu.edu.vn \\ Article history \\ Received: May $13^{\text {th }}, 2018$ \\ Received in revised form: June $10^{\text {th }}, 2018 \mid$ Accepted: June $28^{\text {th }}, 2018$
}

\begin{abstract}
The purpose of strict regulations on probation contracts is to safeguard the rights and legitimate interests of employees and employers in the probation period. The 2012 Labor Code and other related documents extensively update many regulations on probation contracts, but such regulations still retain certain limitations. This paper presents a general overview, describes improvements, and analyses the limitations of current regulations in regard to probation contracts.
\end{abstract}

Keywords: Probation contract; Labor; Probation.

Article identifier: http://tckh.dlu.edu.vn/index.php/tckhdhdl/article/view/469

Article type: (peer-reviewed) Full-length research article

Copyright $(9) 2018$ The author(s).

Licensing: This article is licensed under a CC BY-NC-ND 4.0 


\section{1. ĐẠ̄T VẤn Đî̀}

Quá trình công nghiệp hóa, hiện đại hóa hiện nay cùng với sự phát triển của nền kinh tế cũng là lúc xuất hiện nhiều việc làm mới, thị trường lao động ngày càng phong phú, đa dạng và nhu cầu của NSDLĐ về nguồn nhân lực cũng tăng cao. Từ đó, NSDLĐ phải đặt ra cho mình một cơ chế chặt chẽ trong việc quản lý nhân sự nhằm thu hút cũng như đảm bảo rằng nguồn nhân lực có chất lượng và hiệu quả. Theo đó, một trong những cơ chế đầu tiên mà NLĐ phải đối mặt đó là quá trình thử việc khi được tuyển dụng làm việc cho NSDLĐ thông qua hình thức HĐTV. Ngoài ra, thử việc là một nhu cầu khách quan trong quan hệ lao động (QHLĐ) giữa NLĐ và NSDLĐ. Đó là quá trình để NSDLĐ đánh giá, xem xét về khả năng làm việc, sự đáp ứng yêu cầu công việc của NLĐ. Ngược lại, đây cũng là một bước để NLĐ tự đánh giá, hiểu rõ hơn về khả năng, năng lực của chính bản thân cũng như sự phù hợp với môi trường làm việc của NSDLĐ hay không để đi đến mục tiêu cuối cùng là các bên đồng ý hay không đồng ý với việc xác lập hợp đồng lao động (HĐLĐ) chính thức sau này.

Đối với NLĐ, đây luôn là một thách thức cũng như thời cơ để họ chứng minh khả năng, năng lực của mình đối với NSDLĐ để theo đuổi và làm việc tại nơi mà NLĐ mong muốn. Song song đó, giai đoạn thử việc cũng là mối quan tâm của NLĐ, họ phải làm những gì, thực hiện ra sao và có những quyền lợi, trách nhiệm như thế nào trong thời gian này. Mặc dù, quy định pháp luật lao động hiện hành có nhiều văn bản mới, hướng dẫn chi tiết nhưng quy định liên quan về HĐTV vẫn chưa nhiều, chưa rõ ràng, và còn nhiều điểm hạn chế, tồn tại. Chính vì vậy, nghiên cứu này giúp cho chúng ta có cái nhìn rõ hơn về HĐTV trong giai đoạn hiện nay.

\section{KHÁI QUÁT CHUNG VỀ HợP ĐỒNG THỬ VIỆC}

Khi nghiên cứu quy định pháp luật lao động Việt Nam hiện hành thì hình thức và nội dung thử việc được thể hiện chủ yếu thông qua HĐTV, thể hiện mối QHLĐ trong thời gian thử việc giữa NSDLĐ và NLĐ. Cho đến nay, pháp luật lao động Việt Nam hiện hành không giải thích cụ thể như thế nào về HĐTV, cho nên trong phạm vi bài viết, tác giả dựa vào quy định thử việc tại Điều 26 BLLĐ năm 2012: "NSDLĐ và $N L Đ$ có thể thỏa thuận về việc làm thử, quyền, nghĩa vu của hai bên trong thời gian thư việc. Nếu có thỏa thuận về việc làm thư thì các bên có thể giao kết HĐTV" và khái niệm về HĐLĐ tại Điều 15 BLLĐ năm 2012: "HĐLĐ là sụ thỏa thuận giũa NLĐ và NSDLĐ về việc làm có trả lương, điều kiện làm việc, quyền và nghĩa vu của mối bên trong QHLĐ”. Từ đó, có thể đưa ra khái niệm HĐTV như sau: "HĐTV là sụ thỏa thuận giữa NSDLĐ và NLĐ về việc làm thử, quyền và nghĩa vu của các bên trong thời gian thư viẹc"”.

Về mặt pháp lý thì HĐTV không bắt buộc các bên phải thực hiện, tùy theo nhu cầu và điều kiện của các bên mà có nên thỏa thuận HĐTV hay không. Nếu NLĐ và NSDLĐ có thỏa thuận thì HĐTV là bằng chứng, cam kết có giá trị pháp lý để bảo vệ quyền và lợi ích chính đáng giữa các bên trong thời gian thử việc. Từ khái niệm HĐTV nêu trên, bên cạnh những bản chất của một HĐLĐ nói chung như có sự thỏa thuận bình 
đẳng, song phương, có đối tượng của hợp đồng là việc làm có trả công, thực hiện hợp đồng mang tính đích danh thì HĐTV lại có những đặc trưng pháp lý riêng biệt.

Thứ nhất, HĐTV là một loại hợp đồng nhưng chưa phải là HĐLĐ thực thụ, chưa làm phát sinh QHLĐ chính thức. HĐTV chỉ được coi như một điều kiện trong tuyển dụng lao động. Thử việc đạt yêu cầu, hai bên chủ thể mới tiến hành giao kết HĐLĐ.

Thứ hai, mức độ ràng buộc giữa các bên chủ thể trong hợp đồng này chưa cao, thể hiện trong nội dung HĐTV không đầy đủ như nội dung HĐLĐ. Nội dung HĐTV gồm các nội dung như sau: Tên và địa chỉ NSDLĐ hoặc của người đại diện hợp pháp; Họ tên, ngày tháng năm sinh, giới tính, địa chỉ nơi cư trú, số chứng minh nhân dân hoặc giấy tờ hợp pháp khác của NLĐ; Công việc và địa điểm làm việc; Thời hạn của hợp đồng; Mức lương, hình thức trả lương, thời hạn trả lương, phụ cấp lương và các khoản bổ sung khác; Thời giờ làm việc, thời giờ nghỉ ngơi; Trang bị bảo hộ lao động cho NLĐ. Trong khi đó, vấn đề bảo hiểm xã hội, bảo hiểm y tế cũng như đào tạo, bồi dưỡng, nâng cao trình độ kỹ năng nghề thì chưa được quy định. Mặc khác, còn có yếu tố trong thời gian thử việc các bên có quyền hủy bỏ thỏa thuận thử việc mà không cần báo trước và không phải bồi thường nếu việc làm thử không đạt yêu cầu.

Thứ ba, thời gian thực hiện HĐTV có thể được xác định rõ từ ngày có hiệu lực cho đến khi kết thúc thời gian thử việc. Ở đây, các bên chủ thể mà đặc biệt là NLĐ không có quyền lựa chọn hay làm việc theo ý chủ quan mà công việc phải được thực hiện theo thời gian mà NSDLĐ xác định dựa trên quy định của pháp luật về lao động. Tuy nhiên, thời gian thử việc là thời gian kiểm tra, do vậy $\mathrm{QHL}$ trong thời gian thử việc ràng buộc, khống chế thời hạn về mặt pháp lý hơn HĐLĐ chính thức. Cụ thể, Điều 27 BLLĐ năm 2012 quy định: "Thời gian thư việc căn cú vào tính chất và múc độ phức tạp của công việc nhurng chỉ được thư viẹc một lần đối với một công việc và bảo đảm các điều kiện sau đây: (i) Không quá 60 ngày đối với công việc có chức danh nghề cần trình độ chuyên môn, kỹ thuật tù̀ cao đẳng trở lên; (ii) Không quá 30 ngày đối với công việc có chức danh nghề cần trình độ, chuyên môn, kỹ thuật trung cấp nghề, trung cấp chuyên nghiệp, công nhân kỹ thuật, nhân viên nghiệp vụ; (iii) Không quá 6 ngày làm việc đối với công việc khác".

Thứ tư, việc làm có trả công chính là đối tượng của HĐLĐ nói chung cũng như HĐTV nói riêng. Khi NLĐ tham gia quan hệ thử việc hoàn thành việc làm thử theo như đã thỏa thuận thì NSDLĐ có trách nhiệm trả công cho quá trình làm thử đó nhưng tiền lương của NLĐ trong thời gian thử việc này do hai bên thỏa thuận ít nhất phải bằng $85 \%$ mức lương của công việc chính thức. Vấn đề tiền lương của NLĐ trong thời gian thử việc chính là điểm khác biệt có ý nghĩa quan trọng để phân biệt giữa thử việc và QHLĐ chính thức.

\section{PHÂN BIỆT THỬ VIỆC, TậP SỰ}

Nghiên cứu quy định pháp luật hành chính, lần đầu tiên khái niệm "thử việc" cũng được nhắc đến và chỉ áp dụng đổi với "viên chức" tại Nghị định số 116/2003/NĐCP ngày 10/10/2003 của Chính phủ quy định về việc tuyển dụng, sử dụng và quản lý 
cán bộ, công chức trong các đơn vị sự nghiệp của Nhà nước, tổ chức chính trị, tổ chức chính trị - xã hội (gọi chung là viên chức). Theo đó, "thư việc là quá trình người được tuyển dụng làm thử chức trách, nhiệm vụ của ngạch sẽ được bổ nhiệm sau khi ký hợp đồng làm việc". Tìm hiểu các quy định pháp luật hành chính trước đó, thì các nhà làm luật cũng không dùng thuật ngữ "thử việc" mà họ sử dụng thuật ngữ "thời gian tập sự", "thời gian làm thử". Cụ thể tại Khoản 11 Điều 2 Nghị định 95/1998/NĐ-CP ngày 17/11/1998 của Chính phủ quy định về tuyển dụng, sử dụng và quản lý công chức: "Thời gian tập sụ là thời gian mà người được tuyển dụng sau khi thi tuyển tập làm các chức trách, nhiệm vu của ngạch mà công chức sẽ được bổ nhiệm" và tại Điều 8 Nghị định số 24-CP ngày 08/11/1962 của Hội đồng Chính phủ ban hành Điều lệ tuyển dụng công nhân, viên chức Nhà nước: "Thời gian tập sụ nói chung không được quá hai năm. Bộ Lao động và Bộ Nội vu sẽ quy định cu thể thời gian tập sụ áp dụng cho học sinh tốt nghiệp của tùng loại trường, lớp đào tạo cán bộ, công nhân. Thời gian làm thử, nói chung, không được quá 30 ngày. Xí nghiẹp, co quan tuyển người sẽ quyết định làm thư hoạc miễn thời gian làm thử tùy theo tính chất phức tạp hay giản đơn của công việc mà nguời đó sẽ nhận". Tuy nhiên, tất cả những văn bản này đều đã hết hiệu lực thi hành. Cho đến nay, trong lĩnh vực hành chính thì pháp luật không ghi nhận thuật ngữ "thử việc" nữa mà thay vào đó là sử dụng thuật ngữ "chế độ tập sự" được áp dụng đối với viên chức và công chức.

Ngược lại, khi nghiên cứu quy định của pháp luật lao động Việt Nam hiện hành, thuật ngữ "thử việc" không được định nghĩa một cách cụ thể mà chỉ quy định một cách khái quát nhất định từ Điều 26 đến Điều 29 của BLLĐ năm 2012. Do đó, đây là điểm hạn chế đầu tiên trong quy định pháp luật về thử việc khi không giải thích rõ thuật ngữ này. Mặt khác, hai thuật ngữ "thử việc" và "tập sự" có điểm giống nhau là đều nói lên việc một cá nhân thực hiện một công việc hoặc chức trách, nhiệm vụ của mình nhưng chỉ ở giai đoạn thử thách, tìm hiểu công việc. Tuy nhiên, giữa chúng có những điểm khác nhau được trình bày trong các tiểu mục sau đây.

\subsection{Khái niệm thử việc, tập sự}

Cho đến nay, quy định pháp luật lao động hiện hành cũng như những quy định về thử việc trước đó thì chưa có văn bản quy phạm nào quy định giải thích cụ thể "thử việc" là gì. Song khi nghiên cứu pháp luật thực định, chúng ta có thể thấy rằng thử việc chính là việc NSDLĐ và NLĐ thỏa thuận về việc làm thử trong một khoảng thời gian nhất định trước khi tiến tới giao kết HĐLĐ chính thức. Thử việc là hoạt động hợp pháp cũng như các hoạt động lao động khác theo quy định của pháp luật lao động. Theo đó, có thể hiểu như sau: "Thử việc là hoạt động mà NLĐ thực hiện việc làm thư đối với một công việc nhất định và được NSDLĐ trả luơng tương ưng với việc làm thủ đó”.

Ngược lại, hình thức "tập sự" được quy định theo pháp luật hành chính. Được điều chỉnh cụ thể theo quy định pháp luật về cán bộ, công chức và viên chức. Tuy nhiên, pháp luật hiện hành chỉ quy định chung về chế độ tập sự cho công chức được tuyển dụng và người trúng tuyển viên chức chứ không đưa ra một khái niệm cụ thể nào khác. 
- Đối với công chức: Khoản 1 Điều 20 Nghị định số 24/2010/NĐ-CP ngày 15/3/2010 về tuyển dụng, sử dụng và quản lý công chức quy định như sau: "Người được tuyển dụng vào công chức phải thực hiện chế độ tập sư để làm quen với môi trường công tác, tập làm nhũng công việc của vị trí việc làm được tuyển dụng".

- Đối với viên chức: Khoản 1 Điều 26 Luật Viên chức năm 2010 quy định như sau: "Người trúng tuyển viên chức phải thực hiện chế độ tập sự, trừ trường hợp đã có thời gian từ đủ 12 tháng trở lên thực hiện chuyên môn, nghiệp vụ phù hợp với yêu cầu của vị trí việc làm được tuyển dụng".

\subsection{Chủ thể thực hiện thử việc, tập sự}

Đối với "thử việc" được điều chỉnh theo BLLĐ năm 2012 và những văn bản hướng dẫn thi hành có liên quan thì chủ thể tham gia vào hoạt động thử việc không một ai khác đó chính là NLĐ. Khoản 1 Điều 3 BLLĐ năm 2012 quy định: "NLD là người tù đủ 15 tuổi trở lên, có khả năng lao động, làm việc theo HĐLĐ, được trả luơng và chịu sụ quản lý, điều hành của NSDLD”. Ngược lại, "tập sự” thì chỉ công chức, viên chức là chủ thể thực hiện chế độ tập sự.

Một là, Khoản 2 Điều 4 Luật Cán bộ, Công chức năm 2008 quy định: "Công chức là công dân Việt Nam, được tuyển dụng, bổ nhiệm vào ngạch, chức vụ, chức danh trong co quan của Đảng Cộng sản Việt Nam, Nhà nước, tổ chức chính trị - xã hội ở Trung uoong, cấp tỉnh, cấp huyện; Trong cơ quan, đơn vị thuộc Quân đội nhân dân mà không phải là sĩ quan quân nhân chuyên nghiệp, công nhân quốc phòng; Trong co quan, đơn vị thuộc Công an nhân dân mà không phải là sĩ quan, hạ sĩ quan chuyên nghiệp và trong bộ máy lãnh đạo, quản lý của đơn vị sư nghiệp công lập, trong biên chế, huơơng lương tù ngân sách nhà nước; Đối với công chức trong bọ máy lãnh đạo, quản lý của đơn vị sụ nghiệp công lập thì luơng được bảo đảm tù quỹ luoong của đơn vị sư nghiệp công lập theo quy định của pháp luật”. Theo quy định này thì tiêu chí để xác định công chức gắn với cơ chế tuyển dụng, bổ nhiệm vào ngạch, chức vụ, chức danh. Những người đủ các tiêu chí chung của công chức mà được tuyển vào làm việc trong các cơ quan, đơn vị của Đảng, Nhà nước, tổ chức chính trị - xã hội, bộ máy lãnh đạo, quản lý của đơn vị sự nghiệp công lập thông qua quy chế tuyển dụng, bổ nhiệm vào ngạch, chức vụ, chức danh thì được xác định là công chức. Công chức là những người được tuyển dụng lâu dài, hoạt động của họ gắn với quyền lực công hoặc quyền hạn hành chính nhất định được cơ quan có thẩm quyền trao cho và chịu trách nhiệm trước cơ quan, tổ chức có thẩm quyền về việc thực hiện nhiệm vụ, quyền hạn được giao.

Hai là, Điều 2 Luật Viên chức năm 2010 quy định như sau: "Viên chưc là công dân Việt Nam được tuyển dụng theo vị trí việc làm, làm việc tại đơn vị sụ nghiệp công lập theo chế độ hợp đồng làm việc, hưởng luơng tù quỹ luơng của đơn vị sư nghiệp công lập theo quy định của pháp luật”. Theo đó, viên chức là người được tuyển dụng theo hợp đồng làm việc, được bổ nhiệm vào một chức danh nghề nghiệp, chức vụ quản lý (trừ các chức vụ quy định là công chức). Viên chức là người thực hiện các công việc hoặc nhiệm vụ có yêu cầu về năng lực, kỹ năng chuyên môn, nghiệp vụ trong các đơn vị 
sự nghiệp công lập thuộc các lĩnh vực như giáo dục, đào tạo, y tế, khoa học, công nghệ, văn hóa, tài nguyên môi trường. Quy định về chế độ tập sự không chỉ áp dụng đối với công chức được tuyển dụng mà còn áp dụng đối với viên chức được tuyển dụng. Không áp dụng chế độ tập sự với trường hợp bổ nhiệm công chức, viên chức.

Như vậy, về mặt chủ thể khi tham gia vào hoạt động thử việc hay chế độ tập sự thì chủ thể tham gia vào hoạt động thử việc rộng hơn chể độ tập sự bởi vì bất kỳ NLĐ nào được quy định trong BLLĐ đều có thể tham gia vào hoạt động thử việc, còn chế độ tập sự rất hạn chế về chủ thể, chỉ dành cho đối tượng là công chức và viên chức theo pháp luật về cán bộ, công chức và viên chức.

\subsection{Thời gian thử việc, tập sự}

Theo quy định tại Điều 27 BLLĐ năm 2012 thì thời gian thử việc căn cứ vào tính chất và mức độ phức tạp của công việc, cụ thể như sau: (i) Không quá 60 ngày đối với công việc cần trình độ từ cao đẳng trở lên; (ii) Đối với công việc mà trình độ trung cấp nghề, trung cấp chuyên nghiệp... thì thử việc không quá 30 ngày; và (iii) các công việc khác thì thử việc không quá sáu ngày làm việc.

Ngược lại, đối với công chức, viên chức thì thời gian tập sự quy định khác hơn so với thời gian thử việc, cụ thể như sau: (i) Thời gian tập sự đối với công chức được tuyển dụng vào ngạch chuyên viên hoặc tương đương là 12 tháng; Đối với ngạch cán sự hoặc tương đương và ngạch nhân viên thì thời gian tập sự là sáu tháng (theo Khoản 2 Điều 20 Nghị định 24/2010/NĐ-CP ngày 15/3/2010 quy định về tuyển dụng, sử dụng và quản lý công chức); (ii) Thời gian tập sự đối với viên chức được tuyển dụng là từ ba tháng đến 12 tháng (theo Khoản 2 Điều 27 Luật Viên chức năm 2010).

\subsection{Nội dung, hình thức pháp lý}

Đối với NLĐ: NLĐ có thể thỏa thuận với NSDLĐ về việc làm thử và các bên có thể giao kết hợp đồng thử việc. Ngoài ra, thời gian thử việc căn cứ vào tính chất và mức độ phức tạp của công việc, nhưng chỉ được thử việc một lần không quá 60 ngày đối với công việc có chức danh nghề cần trình độ chuyên môn, kỹ thuật từ cao đẳng trở lên; Không quá 30 ngày đối với công việc có chức danh nghề cần trình độ chuyên môn kỹ thuật trung cấp nghề, trung cấp chuyên nghiệp, công nhân kỹ thuật, nhân viên nghiệp vụ; Không quá sáu ngày làm việc đối với công việc khác. Sau khi kết thúc thời gian thử việc, nếu NLĐ đạt yêu cầu thì NSDLĐ phải giao kết HĐLĐ với NLĐ theo quy định.

Đối với viên chức: Sau khi được tuyển dụng, viên chức sẽ thực hiện việc tập sự, thời gian tập sự sẽ được quy định trong hợp đồng làm việc xác định thời hạn. Sau khi hết thời gian tập sự, nếu người tập sự đạt yêu cầu thì người đứng đầu đơn vị sự nghiệp công lập quyết định hoặc làm văn bản đề nghị cấp có thẩm quyền quản lý viên chức ra quyết định bổ nhiệm chức danh nghề nghiệp đồng thời tiến hành ký kết hợp đồng làm việc không xác định thời hạn đối với viên chức.

Đối với công chức: Việc tập sự không thể hiện thông qua hình thức pháp lý là hợp đồng thử việc hay hợp đồng làm việc. Chế độ tập sự là bắt buộc đối với mọi công 
chức. Điều 40 Luật Cán bộ, Công chức năm 2008 quy định: "Ngườ được tuyển dụng vào công chức phải thực hiện chể độ tập sự theo quy định của Chính phủ”, và Điều 20 Nghị định số 24/2010/NĐ-CP ngày 15/3/2010 về tuyển dụng, sử dụng và quản lý công chức quy định chi tiết chế độ tập sự như sau:

1. Người được tuyển dụng vào công chức phải thực hiện chế độ tập sự để làm quen với môi truờng công tác, tập làm nhũ̃ng công viẹc của vị trí việc làm được tuyển dụng.

2. Thời gian tập sụ được quy định nhu sau: a) 12 tháng đối với truòng hợp tuyển dụng vào công chức loại $C$; b) 06 tháng đối với truoòng hợp tuyển dụng vào công chúc loại $D$; c) Người được tuyển dụng vào công chức dụ bị trước ngày 01 tháng 01 năm 2010 theo quy định của Pháp lệnh Cán bộ, công chức thì chuyển sang thực hiện chế độ tập sụ. Thời gian đã thực hiện chế độ công chưc dư bị được tính vào thời gian tập sụ.

Nhìn chung, chế độ tập sự của công chức cũng giống như các nội dung, thời gian tập sự của viên chức nhưng điều khác cơ bản là chế độ thực hiện tập sự của viên chức được quy định trong hợp đồng làm việc.

Tóm lại, "thử việc" hay "tập sự" đều có điểm giống nhau nhưng giữa chúng có sự khác nhau nhất định qua việc phân tích nêu trên nhằm làm sáng tỏ quy định của pháp luật cũng như áp dụng nó vào thực tiễn. Ngoài ra, sự phân biệt này giúp chúng ta có cách hiểu thống nhất hai thuật ngữ "thử việc" và "tập sự" sao cho phù hợp với thực tế.

\section{NHŨ̉NG HẠN CHỂ CỦA Bộ LUẠT LAO ĐỘNG NĂM 2012 VỀ HợP ĐỒNG THƯ⿱ VIỆC VÀ MỘT Ŝ́ KIẾN NGH!̣}

HĐTV là một vấn đề quan trọng, cơ sở pháp lý đảm bảo quyền và nghĩa vụ các bên trong thời gian thử việc. Những điểm tiến bộ trong quy định về HĐTV của BLLĐ năm 2012 và các văn bản hướng dẫn thi hành là rất đáng ghi nhận. Tuy nhiên, quy định về HĐTV cần được xem xét và hoàn chỉnh:

Một là, chưa có giải thích cụ thể, rõ ràng về khái niệm HĐTV. Thực chất giai đoạn thử việc là giai đoạn các bên tiến hành tiếp xúc, thăm dò lẫn nhau và thực hiện tạm thời để các bên xác lập QHLĐ chính thức sau này. Do đó, ngoài bản chất "thử thách" thì các vấn đề khác trong giai đoạn thử việc cũng giống như một QHLĐ chính thức. Và HĐTV cũng là một loại hợp đồng mà các bên thỏa thuận nhằm thực hiện thử công việc nhất định trước khi ký kết HĐLĐ chính thức. Vì vậy, HĐTV đóng vai trò như là căn cứ pháp lý ràng buộc quyền và nghĩa vụ giữa các bên trong thời gian thử việc này.

Hai là, quy định không rõ ràng về nguyên tắc thử việc một lần và trường hợp NLĐ làm việc theo HĐLĐ mùa vụ không phải thử việc. Hiện tại, pháp luật chỉ cho phép thử việc một lần đối với một công việc và đảm bảo các điều kiện về thời gian thử việc tại Điều 27 BLLĐ năm 2012. Tuy nhiên, quy định như vậy là cứng nhắc, vì trong thực tế vẫn xảy ra những trường hợp thử việc như sau: 
- NLĐ thử việc một lần đối với một công việc, NLĐ thực hiện xong công việc không đạt theo yêu cầu của NSDLĐ dẫn đến chấm dứt thử việc nhưng sau đó NLĐ lại tiếp tục được tuyển dụng lại và tiếp tục thử việc một lần đối với công việc đó nữa. Trường hợp này pháp luật không quy định và cũng không cấm chúng ta thực hiện. Nhưng khi thử việc trong trường hợp này thì tốn kém nhiều thời gian thay vì chúng ta tuyển dụng lao động mới;

- Hoặc là, vì tính chất hoạt động cũng như quy mô sản xuất kinh doanh của NSDLĐ mà NSDLĐ tuyển dụng NLĐ kiêm nhiều công việc (vừa phụ trách hành chính, nhân sự vừa phụ trách kinh doanh...). Điều 27 BLLĐ năm 2012 quy định: "Thời gian thư việc căn cú vào tính chất và mức độ phức tạp của công việc nhung chỉ được thư việc 01 lần đối vói một công việc...". Theo cách hiểu như quy định này thì với mỗi công việc kiêm nhiệm NLĐ sẽ phải bị thử việc một lần, tức nhiều hơn một lần theo quy định. Theo quan điểm của người viết thì trong trường hợp này NLĐ chỉ phải thử việc một lần cho toàn bộ công việc được giao kể cả công việc kiêm nhiệm.

Ngoài ra, về nguyên tắc, nếu NLĐ làm việc theo HĐLĐ mùa vụ thì không phải thử việc (Khoản 2 Điều 26 BLLĐ năm 2012). Đây là quy phạm mang tính bắt buộc nhưng đây không phải là quy định cấm thử việc giữa các bên khi NLĐ làm việc theo HĐLĐ mùa vụ bởi vì cách dùng từ trong nguyên tắc này không phù hợp, chưa rõ như thế nào là "không phải thử việc". Về bản chất của HĐLĐ mùa vụ là không thường xuyên, thời gian tương đối ngắn nhưng nếu các bên có yêu cầu tiến hành thỏa thuận thử việc thì các bên vẫn được thực hiện thử việc cho dù pháp luật quy định rằng HĐLĐ mùa vụ thì không phải thử việc.

Ba là, quy định về nội dung HĐTV một cách cứng nhắc, không linh hoạt. Khi các bên lựa chọn thử việc tức là các bên có thể thỏa thuận HĐTV. Nội dung thỏa thuận khi giao kết HĐTV được quy định tại Khoản 1 Điều 26 của BLLĐ năm 2012. Tuy nhiên, HĐTV cũng có những điểm tương tự như các hợp đồng khác trong quan hệ dân sự mà cụ thể nhất là HĐLĐ. Đó là quyền tự do cam kết, thỏa thuận trong việc xác lập quyền, nghĩa vụ được pháp luật bảo đảm, nếu cam kết, thỏa thuận đó không vi phạm điều cấm của pháp luật, không trái đạo đức xã hội. Theo đó, các nội dung khác nếu không vi phạm điều cấm của pháp luật hay trái đạo đức xã hội thì các bên trong HĐTV đều có thể lựa chọn ngay cả những thỏa thuận liên quan đến chế độ bảo hiểm xã hội, bảo hiểm y tế, chế độ đào tạo và những điều khoản khác có liên quan trong thời gian thử việc. Chẳng hạn, khi giao kết HĐTV hay kể cả HĐLĐ có thời hạn dưới ba tháng thì bắt buộc các bên phải tham gia bảo hiểm xã hội, bảo hiểm y tế thực hiện theo lộ trình áp dụng Luật Bảo hiểm xã hội năm 2014 kể từ ngày 01/01/2018.

Bốn là, quy định về tiêu chí đạt yêu cầu khi kết thúc HĐTV chưa cụ thể, rõ ràng. Thực tế cho thấy, việc đánh giá quá trình thử việc theo các yêu cầu mà các bên tham gia giao kết được NSDLĐ quy định cụ thể trong chính sách tuyển dụng. Tuy nhiên, việc đánh giá còn mang tính chủ quan theo hướng cảm tính của NSDLĐ. Do đó, vấn đề đặt ra là có cần phải có sự đồng thuận của bên còn lại là NLĐ khi tiến hành đánh giá quá trình làm thử. Mặt khác, quy định thời gian thử việc kết thúc thì NSDLĐ phải giao kết 
HĐLĐ khi NLĐ làm thử đạt yêu cầu. Điều này có nghĩa là khi đạt yêu cầu thì bắt buộc NSDLĐ phải giao kết HĐLĐ với NLĐ. Nhưng vấn đề đặt ra thế nào là "đạt yêu cầu" để ký kết HĐLĐ là rất khó, nếu các bên thỏa thuận bằng lời nói hoặc kể cả bằng văn bản nhưng không xác định rõ ràng tiêu chuẩn đạt yểu cầu. Cho nên, khi kết thúc HĐTV, nếu NSDLĐ đưa ra hàng loạt nhận xét mang tính chủ quan thì việc tiếp nhận NLĐ hay không lại phụ thuộc vào chính NSDLĐ.

Năm là, không quy định về trường hợp NLĐ vẫn tiếp tục làm việc khi kết thúc HĐTV. Trong trường hợp sau khi hết hạn HĐTV mà NSDLĐ không đánh giá kết quả công việc để xác định mức độ đạt yêu cầu mà NLĐ vẫn tiếp tục làm việc thì QHLĐ sau đó sẽ như thế nào? Việc làm thử có được coi là đạt yêu cầu hay không? HĐTV có đương nhiên trở thành HĐLĐ hay không? và nếu có thì xếp vào loại hợp đồng nào? Đây là những nội dung mà BLLĐ năm 2012 và các văn bản hướng dẫn thi hành không quy định.

Trên cơ sở xây dựng quy định về HĐTV một cách chặt chẽ, khoa học và đảm bảo quyền và lợi ích hợp pháp của các bên trong thời gian thử việc, tác giả kiến nghị cần thực hiện những giải pháp cơ bản sau:

Thứ nhất, cần bổ sung giải thích khái niệm về HĐTV bên cạnh khái niệm HĐLĐ theo Điều 15 BLLĐ năm 2012. Theo đó, "Hợp đồng thư việc là sư thỏa thuận giữa NLĐ và NSDLĐ về việc làm thư, quyền và nghĩa vu giũa các bên trong thời gian thư việc".

Thứ hai, xây dựng nguyên tắc thử việc một lần sao cho phù hợp đối với trường hợp NLĐ kiêm nhiệm nhiều công việc thì phải thử việc một lần đối với toàn bộ công việc được giao cho NLĐ cũng như quy định trường hợp NLĐ làm việc theo HĐLĐ theo mùa vụ thì không được thử việc, có nghĩa là sau khi chấm dứt HĐTV thì không được ký HĐLĐ theo mùa vụ. Cho nên, cần quy định lại nguyên tắc thử việc một lần để tránh tình trạng tuyển dụng lại và đảm bảo về tổng số lần thử việc như sau: "Thời gian thư việc căn cứ vào tính chất và múc độ phức tạp của công việc nhung chỉ được thư việc một lần đối với toàn bô các công việc đurợc giao cho môt NLĐ và bảo đảm các điều kiện sau: i) Không quá 60 ngày đối với công việc có chức danh nghề cần trình độ chuyên môn, kỹ thuật tù̀ cao đăng trở lên; ii) Không quá 30 ngày đối với công việc có chức danh nghề cần trình độ chuyên môn, kỹ thuật trung cấp nghề, trung cấp chuyên nghiệp, công nhân kỹ thuật, nhân viên nghiệp vu; và iii) Không quá sáu ngày làm việc đối với công việc khác". Đối với HĐLĐ theo mùa vụ, cần chỉnh sửa lại cách dùng từ đối với nguyên tắc thử việc này như sau: "NLĐ làm việc theo HĐLĐ mùa vu thì không được thư việc".

Thứ ba, hoàn thiện quy định về nội dung HĐTV, không chỉ bó gọn trong những nội dung theo quy định hiện tại mà cần tạo thuận lợi cho các bên lựa chọn các nội dung khác để thỏa thuận và xác lập trong HĐTV nhằm có lợi cho các bên, nhất là NLĐ mà vẫn bảo đảm nguyên tắc tự do, tự nguyện giao kết hợp đồng. Ngoài những quyền và nghĩa vụ mà các bên thỏa thuận trong HĐTV pháp luật nên quy định trừ quyền chấm dứt quan hệ làm thử không cần báo trước và không phải bồi thường thì các quyền và nghĩa vụ của các bên trong giai đoạn thử việc cũng được áp dụng giống như NLĐ làm 
việc chính thức. Quy định này sẽ vừa đảm bảo quyền lợi cho NLĐ vừa nâng cao ý thức trách nhiệm của NSDLĐ đối với NLĐ làm thử, hạn chế tình trạng lạm dụng lao động thử việc. Do đó, Đoạn 2 Khoản 1 Điều 26 BLLĐ năm 2012 cần điều chỉnh: "Nội dung của hợp đồng thư việc gồm các nội dung quy định tại các Điểm $a, b, c, d, d, g$ và $h$ tại Khoản 1 Điều 23 của Bộ luật này" thành "Nội dung của hợp đồng thư việc bao gồm các nội dung quy định tại các Điểm $a, b, c, d, d$, g và h tại Khoản 1 Điều 23 của Bộ luật này và các nội dung khác phù hợp với quy định của pháp luật".

Thứ tư, quy định chi tiết tiêu chuẩn về xem xét đạt yêu cầu thử việc, trong quy định này sẽ cho phép các bên tự thỏa thuận về các yêu cầu và mức độ đạt yêu cầu trước khi bắt đầu thời gian thử việc. Trường hợp các bên không tự thỏa thuận thì áp dụng theo quy định pháp luật lao động về đánh giá đạt yêu cầu thử việc sẽ được bổ sung, quy định trong các văn bản hướng dẫn thi hành. Theo đó, "Các tiêu chuẩn đánh giá đạt yêu cầu thư việc bao gồm: (i) Tu tuởng, phẩm chất cá nhân; (ii) Tinh thần trách nhiệm, kỷ luật lao động; (iii) Năng lưc chuyên môn; (iv) Quan hệ đồng nghiệp, cấp trên; (v) Mặt hạn chế; và (vi) Các tiêu chuẩn khác.

Thứ năm, khi kết thúc HĐTV mà NLĐ vẫn tiếp tục làm việc thì cũng cần áp dụng tương tự như trường hợp kết thúc HĐLĐ có thời hạn theo Khoản 2 Điều 22 BLLĐ năm 2012 quy định: "Khi HĐLĐ xác định thời hạn và HĐLĐ theo mùa vu hoạc theo công việc nhất định có thời hạn dưới 12 tháng hết hạn mà NLĐ vẫn tiếp tục làm việc thì trong thời hạ 30 ngày, kể tù ngày HĐLĐ hết hạn, hai bên phải ký kết HĐLĐ mới; Nếu không ký kết HĐLĐ mới thì HĐLĐ xác định thời hạn đã giao kết trở thành HĐLĐ không xác định thời hạn và HĐLĐ theo mùa vu hoặc theo công việc nhất định có thời hạn dưới 12 tháng đã giao kết trở thành HĐLĐ xác định thời hạn với thời hạn là 24 tháng", tức là việc làm thử của NLĐ được coi là đạt yêu cầu và NSDLĐ phải giao kết HĐLĐ với NLĐ. Cho nên, cần phải quy định rõ nội dung này trong văn bản hướng dẫn thi hành để có cơ sở áp dụng khi thực tế xảy ra.

\section{KẾT LUẬn}

Tóm lại, thử việc là một vấn đề pháp lý quan trọng, là yêu cầu tất yếu trong QHLĐ giữa NLĐ và NSDLĐ. Đó là quá trình để NSDLĐ đánh giá, xem xét về khả năng, sự đáp ứng theo yêu cầu công việc của NLĐ. Ngược lại, đây cũng là một bước để NLĐ tự đánh giá về khả năng cũng như sự phù hợp với môi trường làm việc của NSDLĐ thông qua HĐTV. Chính vì vậy, việc hoàn thiện quy định về HĐTV là tiền đề cơ bản đảm bảo tính pháp lý cũng như đảm bảo hài hòa quyền, lợi ích hợp pháp của $\mathrm{NLĐ} \mathrm{và} \mathrm{NSDLĐ} \mathrm{trong} \mathrm{thời} \mathrm{gian} \mathrm{thử} \mathrm{việc} \mathrm{và} \mathrm{tiếp} \mathrm{theo} \mathrm{sau} \mathrm{đó} \mathrm{là} \mathrm{QHLĐ} \mathrm{chính} \mathrm{thức.}$

\section{TÀI LIỆ THAM KHẢO}

Bùi, Q. T. (1957). Luật Lao động dẫn giải. Sài Gòn, Việt Nam: NXB. Khai Trí.

Phan, T. T. (2014). Hợp đồng lao động, thỏa uớc lao động tập thể và giải quyết tranh chấp lao động theo quy định của pháp luật Việt Nam. Hà Nội, Việt Nam: NXB. Tư pháp.

Quốc Hội. (2012). Bộ luật Lao động năm 2012. Hà Nội, Việt Nam: NXB. Lao động. 
Quốc Hội. (2015). Luật Viên chức. Hà Nội, Việt Nam: NXB. Chính trị Quốc gia.

Quốc Hội. (2016). Luật Cán bộ, Công chức. Hà Nội, Việt Nam: NXB. Chính trị Quốc gia.

Trần, H. H. (2015). Giáo trình Luật Lao động. TP. Hồ Chí Minh, Việt Nam: NXB. Hồng Đức. 